\title{
Beta-blocker under-use in COPD patients
}

This article was published in the following Dove Press journal:

International Journal of COPD

17 October 2017

Number of times this article has been viewed

\author{
Kuan Pin Lim ${ }^{1,2}$ \\ Sarah Loughrey' \\ Michael Musk ${ }^{1,2}$ \\ Melanie Lavender ${ }^{1,2}$ \\ Jeremy P Wrobel ${ }^{1-3}$ \\ 'Advanced Lung Disease Unit, \\ Royal Perth Hospital, Perth, WA, \\ Australia; ${ }^{2}$ Respiratory Department, \\ Fiona Stanley Hospital, Murdoch, \\ WA, Australia; ${ }^{3}$ School of Medicine, \\ University of Notre Dame, Fremantle, \\ WA, Australia
}

Correspondence: Kuan Pin Lim Respiratory Department, Fiona Stanley Hospital, Locked Bag I00, Palmyra DC, WA 696I, Australia Email drkplim@gmail.com
Background: Cardiovascular (CVS) comorbidities are common in COPD and contribute significantly to morbidity and mortality, especially following acute exacerbations of COPD (AECOPD). Beta-blockers (BBs) are safe and effective in COPD patients, with demonstrated survival benefit following myocardial infarction. We sought to determine if BBs are underprescribed in patients hospitalized with AECOPD. We also sought to determine inpatient rates of CVS and cerebrovascular complications, and their impact on patient outcomes.

Methods: Retrospective hospital data was collected over a 12-month period. The medical records of all patients $>40$ years of age coded with a diagnosis of AECOPD were analyzed. Prevalent use and incident initiation of BBs were assessed. Comorbidities including indications and contraindications for BB use were analyzed.

Results: Of the 366 eligible patients, 156 patients (42.6\%) had at least one indication for BB use - of these patients, only $53(34.0 \%)$ were on BB therapy and $61(39.1 \%)$ were not on BB therapy but had no listed contraindication. Prevalent use of BBs at the time of admission in all 366 patients was $19.7 \%$, compared with $45.6 \%, 39.6 \%$ and $45.9 \%$ use of anti-platelets, statins and angiotensin-converting enzyme inhibitor/angiotensin II receptor blockers, respectively. CVS and cerebrovascular complications were common in this population (57 patients, $16 \%)$ and were associated with longer length of stay $(p<0.01)$ and greater inpatient mortality $(p=0.02)$.

Conclusions: BBs are under-prescribed in COPD patients despite clear indication(s) for their use. Further work is required to explore barriers to BB prescribing in COPD patients.

Keywords: COPD exacerbations, beta-blockers, cardiovascular, comorbidity

\section{Introduction}

COPD remains a major cause of mortality and morbidity across the world. The World Health Organization listed COPD as the fourth leading cause of death worldwide (alongside lower respiratory infections) in 2015, resulting in an estimated 3.17 million deaths that year.

Acute exacerbations of COPD (AECOPD) carry a poor prognosis with a calculated 1 - and 2 -year mortality of $22 \%$ and $36 \%$, respectively. ${ }^{2,3}$ Patients with frequent exacerbations have more than 4 times risk of death compared with non-exacerbators. ${ }^{4}$

There is increasing focus in medical literature on COPD comorbidities. ${ }^{5-8}$ The Global Initiative for Chronic Obstructive Lung Disease guidelines (2016) dedicate a full chapter to the management of comorbidities in COPD, emphasizing their importance. ${ }^{7}$ COPD patients are at higher risk of CVS disease. CVS disease is associated with high morbidity and mortality in COPD patients. ${ }^{8-10}$ The ECLIPSE group showed that CVS disease was an independent risk factor for mortality after adjusting for age, gender and smoking history in their cohort of 2,164 patients. ${ }^{9}$ The estimated mortality hazard ratio of having concurrent heart failure (HF) in COPD patients compared with those without HF is 1.3-1.9; concurrent ischemic heart disease (IHD) has a hazard ratio of 1.27-1.5; and concurrent atrial fibrillation/flutter has a 
hazard ratio of $1.56 .^{8-10}$ The optimum management of CVS comorbidities in COPD has not been fully ascertained.

Beta-blockers (BBs) have proven mortality benefit in patients with IHD and HF. ${ }^{11-14}$ Subgroup analysis of postmyocardial infarction (post-MI) patients has shown a consistent beneficial effect in patients with concurrent COPD. ${ }^{11,12}$ Registry data also points to improved survival in post-MI COPD patients initiated early on beta-blockade therapy. ${ }^{15}$ There may even be beneficial effects of BBs in COPD patients independent from CVS effects. Indeed, in a Scottish retrospective cohort study conducted in 2011 by Short et al using the TARDIS database, use of BBs was associated with $22 \%$ reduction in all-cause mortality as well as reduction in need of emergency oral corticosteroid use and hospital admissions. ${ }^{16}$

There has previously been debate about the safety of BBs in patients with COPD. A Cochrane meta-analysis conducted in 2011 demonstrated the safety of BB use in COPD, showing no significant change in forced expiratory volume in $1 \mathrm{~s}\left(\mathrm{FEV}_{1}\right)$, respiratory symptoms or $\mathrm{FEV}_{1}$ response to bronchodilators when compared with placebo. ${ }^{17}$ This includes COPD patients with $\mathrm{FEV}_{1}<50 \%$ predicted or $1.4 \mathrm{~L}$ and those with reversible airflow limitation. Nevertheless, there remains a persisting reluctance from physicians to prescribe BBs in COPD patients primarily because of the perceived risk of inducing bronchospasm.

\section{Aims}

In order to determine local prescribing practices of BBs, we examined hospital inpatients at a major tertiary hospital admitted with an AECOPD. The primary aim of the study was to measure prevalent rates at time of hospitalization of appropriate BB use in this group of COPD patients. We also sought to determine the rates of CVS and cerebrovascular (CVA) events during acute COPD exacerbation admissions, and examined their impact on hospital length of stay, intensive care unit (ICU) admissions and in-patient mortality.

\section{Methods}

We conducted a retrospective cohort study on patients $>40$ years of age admitted with AECOPD over 1 year (1 January 2012 to 31 December 2012) in a large tertiary metropolitan hospital. For patients with repeat admissions during the year, only the first admission was included in the analysis. Data was collected from hospital electronic databases and discharge summaries.

Appropriate use of BBs was defined as having at least 1 indication for use in the absence of contraindications. We defined indications for BB therapy as having a history of IHD, congestive cardiac failure (CCF) and tachyarrhythmias.
Contraindications included a history of BB allergy, bradyarrhythmias, asthma, peripheral vascular disease and hypotension.

IHD events included any of the following: ST-elevation MI, non-ST elevation MI, unstable angina or stable angina. CVA events included ischemic stroke, hemorrhagic stroke and transient ischemic attack.

This project was approved by the Royal Perth Hospital Human Research Ethics Committee (EC00270/HREC REG 14-045). The Committee approved waiver of patient consent, as this was classified a negligible-risk study. De-identified data was used throughout the study.

Statistical analysis was performed on Stata ${ }^{\circledR}$ software. Student's independent $t$-test, Chi square and Fisher's exact tests were used for inter-group comparisons with an alphaerror cutoff of 0.05 .

\section{Results}

A total of 572 admissions were retrieved on initial clinical coding screen. 366 patients were included in the data analysis (Figure 1). The basic patient demographics and clinical outcomes are shown in Table 1.

\section{Prevalence of appropriate use of BBs at the time of admission}

The prevalence of BB use on admission was 19.7\% (72 of 366). Of all patients, $42.6 \%$ (156 of 366) had at least 1 indication for BB use. Of these patients, $34.0 \%$ (53 of 156) were on BBs, $39.1 \%$ (61) were not on BBs and had no known contraindications for their use, and $26.9 \%$ (42) were not on BBs and had known potential contraindications (Figure 1). The breakdowns of the indications and contraindications to BB use are listed in Table 2.

\section{Cardioselective and non-cardioselective BBs}

Sixty-two out of the 72 (86.1\%) patients on BB therapy at the time of admission were on cardioselective BBs (metoprolol 28 , bisoprolol 18, atenolol 11, nebivolol 5). The 8 patients who were initiated on BB therapy during their admission were all commenced on cardioselective BBs (metoprolol 8).

Table I Patient demographics and clinical outcomes

Number of males/females: 208/I58 (ratio I.3:I)

Mean age: 72.7 years $( \pm 12.1$ SD)

Mean length of stay: 5.1 days ( \pm 5.5 SD)

Median length of stay: 3 days (interquartile range $=2-6$ )

Number of ICU admissions: 7 (1.9\%)

Number of deaths: II (3.0\%)

Abbreviation: ICU, intensive care unit. 


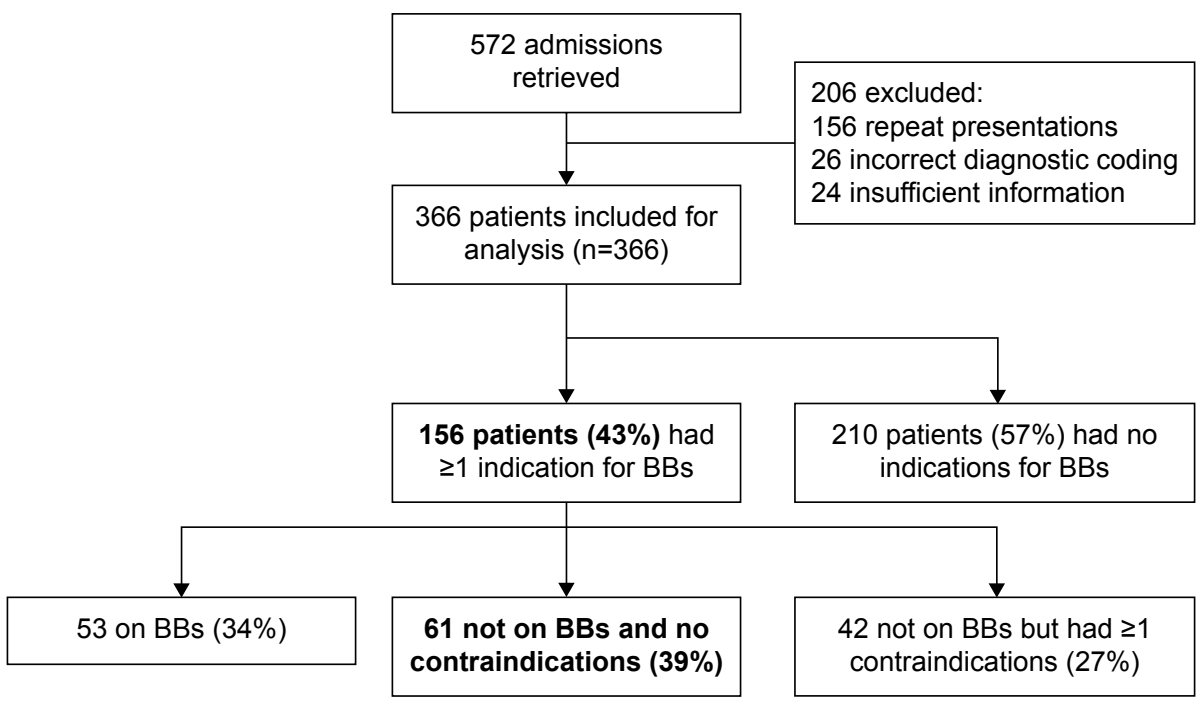

Figure I CONSORT diagram.

Note: Text/data shown in bold are the important points.

Abbreviation: $\mathrm{BB}$, beta-blocker.

\section{Inter-group analyses}

We performed inter-group outcome analyses to detect trends. It is important to note that these analyses were not adjusted for confounders and the study was not powered to detect outcome differences.

We compared the outcomes between AECOPD patients on BB therapy on admission $(n=72)$ and patients not on BB therapy on admission $(\mathrm{n}=294)$. There were more in-hospital incident $\mathrm{CCF}$ events in the on-therapy group $(p<0.01)$ compared with the off-therapy group. However, patients in the on-therapy group were also more likely to have a history of HF $(p<0.01)$ or IHD $(p<0.01)$. There were no statistically significant differences in length of stay, mortality, intensive care admissions, or in-hospital incident tachyarrhythmia, IHD or CVA events.

We then compared the outcomes between AECOPD patients with at least 1 indication for BB use and were appropriately on $\mathrm{BB}(\mathrm{n}=53)$, and patients with at least 1 indication

Table 2 Indications and contraindications for beta-blocker use

\begin{tabular}{|c|c|}
\hline & $\begin{array}{l}\text { Percentage of } \\
\text { patients, \% }(n=366)\end{array}$ \\
\hline \multicolumn{2}{|l|}{ Indications } \\
\hline Ischemic heart disease & $33.1(121)$ \\
\hline Congestive cardiac failure & $15.8(58)$ \\
\hline Tachyarrhythmias & II.2(4I) \\
\hline At least I indication & $42.6(156)$ \\
\hline More than I indication & $15.0(55)$ \\
\hline \multicolumn{2}{|l|}{ Contraindications } \\
\hline Beta-blocker allergy & $0.3(I)$ \\
\hline Asthma & $17.8(65)$ \\
\hline Peripheral vascular disease & $5.7(2 \mathrm{I})$ \\
\hline Bradyarrhythmias & $7.7(28)$ \\
\hline Hypotension & $3.0(11)$ \\
\hline At least I contraindication & 31.7 ( 116$)$ \\
\hline
\end{tabular}

Note: Values shown in bold are the important points. and no contraindication but were inappropriately not on BB ( $n=61)$. In the mortality analysis, there were fewer deaths in the appropriately treated group (0 out of 53) compared with the group that were inappropriately not on BB therapy (6 out of 61), but this did not reach statistical significance ( $p=0.063$ by Fisher's exact test). There were no statistically significant differences in length of stay, or in-hospital incident tachyarrhythmia, IHD, CCF or CVA events.

\section{CVS drug prescribing patterns}

We compared the prescribing practices of $\mathrm{BBs}$ compared with other CVS drugs. 19.7\% of patients with AECOPD were prescribed $\mathrm{BBs}$, while $45.6 \%$ were on anti-platelet medications, $39.6 \%$ on statins and $45.9 \%$ on angiotensinconverting enzyme inhibitor/angiotensin II receptor blockers (ACEi/ARBs) (Table 3). In patients with a documented

Table 3 Prevalent use of cardiovascular drugs in AECOPD patients

\begin{tabular}{lllll}
\hline & $\begin{array}{l}\text { Beta- } \\
\text { blocker, \% }\end{array}$ & $\begin{array}{l}\text { Anti-platelet } \\
\text { drug, \% }\end{array}$ & Statin, \% & $\begin{array}{l}\text { ACEi/ } \\
\text { ARB, \% }\end{array}$ \\
\hline $\begin{array}{l}\text { \% baseline use } \\
\text { in all AECOPD } \\
\text { patients ( } n=366)\end{array}$ & 19.7 & 45.6 & 39.6 & 45.9 \\
\hline $\begin{array}{l}\% \text { prevalent use } \\
\text { in patients with }\end{array}$ & 16 & 48 & 44 & 44 \\
$\begin{array}{l}\text { incident IHD } \\
\text { events ( } n=25)\end{array}$ & & & & \\
\hline $\begin{array}{l}\% \text { prevalent use } \\
\text { in patients with } \\
\text { previous history } \\
\text { of IHD ( } n=16)\end{array}$ & 25 & 75 & 68.8 & 68.8 \\
\hline
\end{tabular}

Abbreviations: ACEi, angiotensin converting enzyme inhibitor; AECOPD, acute exacerbation of chronic obstructive pulmonary disease; ARB, angiotensin II receptor blocker; IHD, ischemic heart disease. 
Table 4 Initiation of cardiovascular drugs in AECOPD patients with new IHD events

\begin{tabular}{|c|c|c|c|c|}
\hline$n=25$ & $\begin{array}{l}\text { Beta- } \\
\text { blocker }\end{array}$ & $\begin{array}{l}\text { Anti-platelet } \\
\text { drug }\end{array}$ & Statin & ACEi/ARB \\
\hline $\begin{array}{l}\% \text { incident initiation of } \\
\text { therapy in treatment- } \\
\text { naïve patients }\end{array}$ & $\begin{array}{l}14.3 \% \\
(3 \text { of } 21)\end{array}$ & $\begin{array}{l}76.9 \% \\
(10 \text { of } 13)\end{array}$ & $\begin{array}{l}28.6 \% \\
(4 \text { of } 14)\end{array}$ & $\begin{array}{l}14.3 \% \\
(2 \text { of } 14)\end{array}$ \\
\hline
\end{tabular}

Abbreviations: ACEi, angiotensin converting enzyme inhibitor; AECOPD, acute exacerbation of chronic obstructive pulmonary disease; ARB, angiotensin II receptor blocker; IHD, ischemic heart disease.

history of IHD, the prevalence of BB use was $25 \%$, compared with $75 \%$ anti-platelet use, $68.8 \%$ statin use and $68.8 \%$ ACEi/ARB use.

\section{Patients with incident IHD events during admission}

Twenty-five out of 366 patients $(6.8 \%)$ had an incident IHD event during their inpatient stay. Sixteen of the 25 patients (64\%) had a prior history of IHD; however, only 4 out of the 25 patients $(16 \%)$ were on BB therapy. In treatment-naïve patients with new IHD events, $14.3 \%$ were commenced on a BB during the admission, compared with $76.9 \%$ commenced on anti-platelet therapy (Table 4).

\section{CVS and CVA events}

CVS and CVA events occurred frequently in our cohort of AECOPD patients. Fifty-seven out of 366 patients (15.6\%)

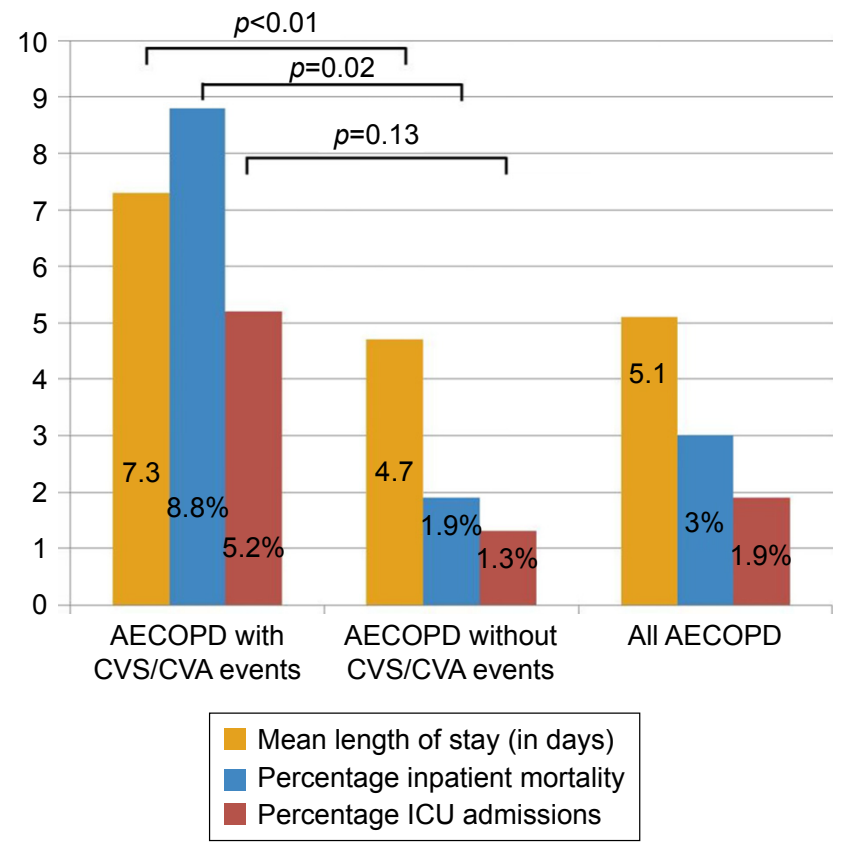

Figure 2 Clinical endpoints for AECOPD patients stratified by incidence of cardiovascular or cerebrovascular events.

Abbreviations: AECOPD, acute exacerbation of chronic obstructive pulmonary disease; CVS, cardiovascular; CVA, cerebrovascular; ICU, intensive care unit. had CVS and/or CVA events during their admission. A total of $70 \mathrm{CVS} / \mathrm{CVA}$ events were identified: CCF exacerbations were the most common (27), followed by IHD events (25), tachyarrhythmias (16) and strokes (2).

In-hospital CVS/CVA events were associated with a longer mean hospital length of stay (7.3 days vs 4.7 days, $p<0.01)$ and a higher inpatient mortality $(8.8 \%$ vs $1.9 \%$, $p=0.02$; Figure 2). A greater percentage of patients with CVS/CVA events had ICU admissions (5.2\% vs $1.3 \%$, $p=0.13$ ), but this was not statistically significant.

\section{Discussion}

Our results show that BBs are under used in patients admitted with AECOPD despite indication(s) for their use. Some of these patients had significant cardiac histories with no contraindication for use. This highlights a disparity between the existing evidence base and routine clinical practice, which may be detrimental to the care of this high-risk group of patients.

Our results complement those described by Neef et al in a separate Australian state, which showed only $51 \%$ of patients with a history of heart failure with reduced ejection fraction and $\mathrm{COPD}$, and $31 \%$ of patients with a history of previous $\mathrm{MI}$ and COPD, were on BBs at the time of admission. ${ }^{18}$

The prevalent use of CVS drugs were comparable with the UK EXODUS cohort reported by Harrison et al - 17\% of patients were on BBs at baseline, $42 \%$ statins, $50 \% \mathrm{ACEi} /$ ARBs, $46 \%$ aspirin and 7\% clopidogrel in the EXODUS cohort $(\mathrm{n}=1,343)$ compared with $20 \% \mathrm{BBs}, 40 \%$ statins, $46 \% \mathrm{ACEi} / \mathrm{ARBs}$ and $46 \%$ anti-platelets (any) in our cohort $(\mathrm{n}=366) .{ }^{19}$ This indicates that BB under-prescribing is not an isolated problem and perhaps reflects physicians' persistent hesitancy in prescribing BBs in COPD patients.

Furthermore, our data shows that the under-use of BB therapy holds true in patients with new cardiac events during their admission for AECOPD. BBs are poorly prescribed compared with other CVS drug classes, suggesting ongoing hesitancy regarding safety of initiation in COPD patients. A COPD patient suffering an inpatient IHD event is 5.5 times more likely to be started on an anti-platelet agent than a BB. This shows a deviation from evidence-based practice.

Our cohort had a high prevalence ( 1 in 6 ) of CVS or CVA events during their admission and this resulted in increased mortality and length of stay. These findings are consistent with previous studies, which also indicate a startlingly high frequency of these events. ${ }^{6-10}$ Donaldson et al report incidence rates of 1.1 MIs per 100 patient-years and 1.4 stroke per 100 patient-years in a cohort of 25,857 COPD exacerbation patients. ${ }^{20}$ Cause-specific mortality analysis of the TORCH 
study cohort indicated that $27 \%$ of the 911 deaths were attributed to CVS causes. ${ }^{21}$ Indeed, it has been shown that cardiac dysfunction during COPD exacerbations and arrhythmogenic sympathetic activation may be major contributors to morbidity and should be viewed as an important therapeutic targets. ${ }^{22,23}$

There is some evidence from observational data that $\mathrm{BBs}$ in COPD may reduce all-cause mortality or at least improve outcomes, including exacerbation frequency. ${ }^{13-18,24,25}$ Perhaps there is a role for BBs in all COPD patients. There is an ongoing prospective multi-center, double-blinded, placebo-controlled randomized trial ( $\beta$ LOCK COPD) recruiting moderate-to-severe COPD patients with no absolute indication for $\mathrm{BB}$ therapy to treatment with metoprolol vs placebo with the primary outcome measure being time to first exacerbation of COPD (secondary outcomes include frequency of exacerbations and mortality). ${ }^{26}$

The management of COPD comorbidities is vital in the overall optimal treatment algorithm of the disease. Safe and effective use of cardioselective BBs in COPD patients is likely going to be an important piece of the puzzle. The correct choice of $\mathrm{BB}$ is likely to be crucial. ${ }^{27-29}$ There may also be a subset of severely unwell patients in whom BB initiation carries higher risk of morbidity. ${ }^{29,30}$

\section{Limitations}

We accept that there are limitations to this study. First, this is a retrospective study looking primarily at electronic discharge summaries and medication prescriptions. Second, the diagnoses labeled were clinical or historical. We did not have full data on spirometric diagnosis of COPD nor did we have echocardiogram reports on severity of left ventricular dysfunction. Third, our definitions on contraindications were intentionally broad. While this may overestimate the true prevalence of contraindications to $\mathrm{BBs}$, it was intentional so that any bias would be toward the null hypothesis. Finally, we also intentionally excluded hypertension as an indication for BB therapy so as not to overestimate the under-utilization of BBs. Although BBs are often used for this indication, there are other classes of medication that may be used in its place.

Our data adds to evidence of BB under-prescribing in this high-risk population of patients. It indicates the need to review prescribing practices in COPD patients with cardiac comorbidities. We suggest: 1) Regular audit of BB and CVS drugs prescribing practices in COPD patients in both inpatient and outpatient settings. 2) Education across other medical specialties about the safety and potential benefits of BBs in COPD patients. 3) Safety and governance review of BB-associated morbidity in COPD patients to identify potential subgroups who may not be suitable for this line of treatment. 4) Collaborative research toward defining the optimal place of BB therapy in COPD management. This should include studies on secondary and tertiary prevention of comorbid CVS events, longitudinal cohort studies to assess long-term safety profiles of therapy, and intervention trials with relevant clinical outcomes like mortality, exacerbation frequency, rate of lung function decline and CVS or nonCVS morbidity.

The take-away message is: if a COPD patient has an absolute indication for BB use (and no contraindication), consider prescribing one.

\section{Disclosure}

The authors report no conflicts of interest in this work.

\section{References}

1. World Health Organization Factsheet. Chronic obstructive pulmonary disease (COPD); Fact sheet; November 2016. Available at: http:// www.who.int/mediacentre/factsheets/fs315/en/. Accessed March 23, 2017.

2. Groenewegen KH, Schols AM, Wouters EF. Mortality and mortalityrelated factors after hospitalization for acute exacerbation of COPD Chest. 2003;124(2):459-467.

3. Almagro P, Calbo E, Ochoa de Echagüen A, et al. Mortality after hospitalization for COPD. Chest. 2002;121:1441-1448.

4. Soler-Cataluña JJ, Martínez-García MÁ, Román Sánchez P, Salcedo E, Navarro M, Ochando R. Severe acute exacerbations and mortality in patients with chronic obstructive pulmonary disease. Thorax. 2005; 60:925-931.

5. Fabbri LM, Luppi F, Beghe B, Rabe KF. Complex chronic comorbidities of COPD. Eur Respir J. 2008;31:204-212.

6. Soriano JB, Visick GT, Muellerova H, Payvandi N, Hansell AL. Patterns of comorbidities in newly diagnosed COPD and asthma in primary care. Chest. 2005;128(4):2099-2107.

7. Global Initiative for Chronic Obstructive Lung Disease (GOLD). Global strategy for diagnosis, management, and prevention of COPD; 2016. Available from: http://goldcopd.org/global-strategy-diagnosismanagement-prevention-copd-2016/. Accessed January 18, 2016.

8. Smith MC, Wrobel JP. Epidemiology and clinical impact of major comorbidities in patients with COPD. Int J COPD. 2014;9:871-888.

9. Miller J, Edwards LD, Agustí A, et al; for ECLIPSE investigators. Comorbidity, systemic inflammation and outcomes in the ECLIPSE cohort. Respir Med. 2013;107:1376-1384.

10. Divo M, Cote C, de Torres JP, et al; for BODE Collaborative Group. Comorbidities and risk of mortality in patients with chronic obstructive pulmonary disease. Am J Respir Crit Care Med. 2012;186(2): $155-161$.

11. Gottlieb SS, McCarter RJ, Vogel RA. Effect of beta-blockade of mortality among high-risk and low-risk patients after myocardial infarction. N Engl J Med. 1998;339(8):489-497.

12. Hawkins NM, Huang Z, Pieper KS, et al. Chronic obstructive pulmonary disease is an independent predictor of death but not atherosclerotic events in patients with myocardial infarction: analysis of the Valsartain in Acute Myocardial Infarction Trial (VALIANT). Eur J Heart Fail. 2009;11(3):292-298.

13. MERIT-HF Study Group. Effect of metoprolol CR/XL in chronic heart failure: metoprolol $\mathrm{CR} / \mathrm{XL}$ randomized interventional trial in heart failure (MERIT-HF). Lancet. 1999;353(9169):2001-2007.

14. Packer M, Fowler MB, Roecker EB, et al; for COPERNICUS Study Group. Effect of carvediolol on the morbidity of patients with severe chronic heart failure. Circulation. 2002;106(17):2194-2199. 
15. Quint JK, Herrett E, Bhaskaran K, et al. Effect of $\beta$ blockers on mortality after myocardial infarction in adults with COPD: population based cohort study of UK electronic healthcare records. BMJ. 2013; 347:f6650.

16. Short PM, Lipworth SW, Elder DHJ, Schembri S, Lipworth BJ. Effect of $\beta$ blockers in treatment of chronic obstructive pulmonary disease: a retrospective cohort study. BMJ. 2011;342:d2549.

17. Salpeter SR, Ormiston TM, Salpeter EE. Cardioselective beta-blockers for chronic obstructive pulmonary disease. Cochrane Database Syst Rev. 2005;(4):CD003566.

18. Neef PA, McDonald CF, Burrell LM, Irving LB, Johnson DF, Steinfort DP. Beta-blockers are under-prescribed in patients with chronic obstructive pulmonary disease and co-morbid cardiac disease. Intern Med J. 2016;46(11):1336-1340.

19. Harrison MT, Short P, Williamson PA, Singanayagam A, Chalmers JD, Schembri S. Thrombocytosis is associated with increased short and long term mortality after exacerbation of chronic obstructive pulmonary disease: a role for antiplatelet therapy. Thorax. 2014;69(7): 609-615.

20. Donaldson GC, Hurst JR, Smith CJ, Hubbard RB, Wedzicha JA. Increased risk of myocardial infarction and stroke following exacerbation of COPD. Chest. 2010;137(5):1091-1097.

21. MacGarvey LP, John M, Anderson JA, Zvarich M, Wise RA. Ascertainment of cause-specific mortality in COPD: operations of the TORCH Clinical Endpoint Committee. Thorax. 2007;62(5): 411-415.

22. MacDonald MI, Shafuddin E, King PT, Chang CL, Bardin PG, Hancox RJ. Cardiac dysfunction during exacerbations of chronic obstructive pulmonary disease. Lancet Respir Med. 2016;4(2):138-148.
23. Laratta CR, van Eeden S. Acute exacerbation of chronic obstructive pulmonary disease: cardiovascular links. Biomed Res Int. 2014;2014: 528789.

24. Dransfield MT, Rowe SM, Johnson JE, Bailey WC, Gerald LB. Use of $\beta$ blockers and the risk of death in hospitalized patients with acute exacerbations of COPD. Thorax. 2008;63(4):301-305.

25. Du Q, Sun Y, Ding N, Lu L, Chen Y. Beta-blockers reduced the risk of mortality and exacerbation in patients with COPD: a meta-analysis of observational studies. PLoS One. 2014;9(11):e113048.

26. Bhatt SP, Connett JE, Voelker H, et al. $\beta$-blockers for the prevention of acute exacerbations of chronic obstructive pulmonary disease ( $\beta$ BLOCK COPD): a randomized controlled study protocol. BMJ Open. 2016; 6(6):e012292.

27. Jabbour A, Macdonald PS, Keogh M, et al. Differences between betablockers in patients with chronic heart failure and chronic obstructive pulmonary disease: a randomized crossover trial. J Am Coll Cardiol. 2016;55(17):1780-1787.

28. Lainscak M, Podbregar M, Kovacic D, Rozman J, von Haehling S. Differences between bisoprolol and carvedilol in patients with chronic heart failure and chronic obstructive pulmonary disease: a randomized trial. Respir Med. 2011;105(Suppl 1):S44-S49.

29. Stefan MS, Rothberg MB, Priya A, Pekow PS, Au DH, Lindenauer PK. Association between beta-blocker therapy and outcomes in patients hospitalized with acute exacerbations of chornic obstructive lung disease with underlying ischemic heart disease, heart failure or hypertension. Thorax. 2012;67(11):977-984.

30. Ekström MP, Hermansson AB, Ström KE. Effects of cardiovascular drugs on mortality in severe chronic obstructive pulmonary disease. Am J Respir Crit Care Med. 2013;187(7):715-720.
International Journal of COPD

\section{Publish your work in this journal}

The International Journal of COPD is an international, peer-reviewed journal of therapeutics and pharmacology focusing on concise rapid reporting of clinical studies and reviews in COPD. Special focus is given to the pathophysiological processes underlying the disease, intervention programs, patient focused education, and self management protocols.

\section{Dovepress}

This journal is indexed on PubMed Central, MedLine and CAS. The manuscript management system is completely online and includes a very quick and fair peer-review system, which is all easy to use. Visit http://www.dovepress.com/testimonials.php to read real quotes from published authors. 